Journal of Social Sciences 5(3): 223-235, 2009

ISSN 1549-3652

(C) 2009 Science Publications

\title{
Consumer Satisfaction with Public Health Care in China
}

${ }^{1}$ Linghui Jiang, ${ }^{2}$ Christopher Gan, ${ }^{3}$ Betty Kao, ${ }^{4}$ Yiyun Zhang, ${ }^{5}$ Hechuan Zhang and ${ }^{6}$ Long Cai

${ }^{1}$ Community Health Project, Save the Children UK China Program, 19th Floor,

China Post Building, No.139 Wu Jing Road, Kunming, Yunnan, Republic of China 650031,

${ }^{2}$ Department of Accounting, Economics and Finance, Faculty of Commerce,

P.O. Box 84, Lincoln University, Canterbury, New Zealand

${ }^{3}$ Distrisurvey Ltd., Room F, 2F.-1, No.148, Yucheng St., Nangang District, Taipei City 115, Taiwan

${ }^{4}$ Yunnan Health and Development Association, P.O. Box 43, Kunming Medical College,

No. 191 West Renmin Road, Kunming, Yunnan, Republic of China, 650031

${ }^{5}$ Department of Social Work, Yunnan University of Finance and Economics,

No. 237 Longquan Road, Kunming, Yunnan, Republic of China 650221

${ }^{5}$ Community Health Project, Save the Children UK China Program, 19th Floor, China Post

Building, No.139 Wu Jing Road, Kunming, Yunnan, Republic of China

\begin{abstract}
Problem statement: Consumer satisfaction is regarded as one of the ultimate goals that all health system should strive for (Hsiao, 2003), it reflects the effectiveness of the health system in consumers' prospect. Yet public health care services in developing countries including Greater Mekong Sub-region (GMS) have failed to achieve adequate level of services. China, for example, satisfaction of public health care is considerably low. To improve public participation and effectiveness of the undergoing health reform initiatives in China, one must understand the underlying factors that contribute to consumer satisfaction for public health services. Approach: Therefore, this study explored the factors associated with consumers' satisfaction with public health care delivery among residents in Kunming city, Yunnan Province of China. Results: Personal interviews with structured-questionnaires were used to collect the data via a convenience sampling of 569 Kunming adult residents who had consulted a doctor for outpatient services in the public health facilities within the past 12 months. The survey questions were designed to gauge the respondents' health care use preferences, satisfaction levels, perceived quality and efficiency of public healthcare including their socio-economic characteristics. Consumers' satisfaction in public health care delivery, factors such as interaction, qualification, financial affordability, environment, physical accessibility, adequate doctors, confidentiality, pricing, corruption and consumers' socio-demographic characteristics were examined using the logistic regression. Conclusion/Recommendations: The results revealed that corruption have a negative impact on consumer satisfaction and perceived as a threat to consumer satisfaction. On the other hand, qualified doctors, affordable costs, adequate doctors and reasonable pricing of public health services were important factors to increase the probability of consumer satisfaction with public health care delivery and should be managed in priority.
\end{abstract}

Key words: Public health care delivery, consumer satisfaction, affordability

\section{INTRODUCTION}

The rights to attainable standard health are regarded as a fundamental human right worldwide, in which everyone regardless of gender, age and income are entitled to. To fully realize this right, governments are obligated to create conducive conditions, which would assure people of universal access to health care in the event of sickness.
Effective progress in health depends vitally on well defined health systems. According to Hsiao (2003), all health systems are designed to achieve three ultimate goals, that is, improving citizen health, providing financial protection against health risks and improving overall consumer satisfaction with the health care system.

However, there are a number of similar challenges facing all the health systems worldwide, including

Corresponding Author: Christopher Gan, Department of Accounting, Economics and Finance, Faculty of Commerce, P.O. Box 84, Lincoln University, Canterbury, New Zealand Tel: 64-3-325-2811 Fax: 64-3-325-3847 
ensuring equitable access to health care services, raising the quality of health care, sustainable financing, greater responsiveness to the citizens' demands, citizen involvement in decision making and reducing barriers between health and social care ${ }^{[13]}$.

Health care delivery in developing countries, including the Greater Mekong Subregion (GMS) countries, has a greater room for improvement, in terms of quality, responsiveness to patients, efficiency, cost escalation and equity. Public health care systems in the GMS countries have failed to deliver adequate level of services, especially to the disadvantaged groups, such as the poor ${ }^{[38]}$. First, access to public health care is limited, due to financial barriers compounded by physical barriers such as availability and accessibility of health facilities. Secondly, public health worker morale is poor, as salaries in the public sector are very low in many countries. Public health workers are also involved in some form of private practices and unofficially charge for certain services in public health facilities. The profit-driven practices by public health facilities and workers significantly undermine the quality of health care and responsiveness to patients.

As a result of poor public health care delivery, the utilization of public health services is actually decreasing in some areas, particularly among some vulnerable social groups. Discontent with the current situation is continually increasing among the general population and significant improvement in the public health care delivery is eminent. For example, a poll of 733 respondents revealed that $90 \%$ of the people are not satisfied with the health care delivery reform in the past decade in China ${ }^{[41]}$. The public appeal for an effective reform of the health system has reached to a peak in 2007 putting great pressure on the administration for significant changes ${ }^{[34]}$.

To meet such complex challenges, many countries are reforming their health sector and system. The different strategies for reform include decentralization and centralization, substitution policies, redefinition of the functions of hospitals and primary care, creation of new roles for professionals, improved management, cost-containment and market orientation. Regardless of the strategy adopted, the aims of reform are to provide health care accessible to all citizens focusing on the effective and efficient delivery mechanism to increase consumers' satisfaction ${ }^{[45,46]}$.

According to the World Health Organization ${ }^{[44]}$, one of the fundamental goals of any health system is to respond to consumer expectations:

- In particular, people have a right to expect that the health system will treat them with individual dignity... their needs should be promptly attended to, without long delays in waiting for diagnosis and treatment-not only for better health outcomes but also to respect the value of people's time and to reduce their anxiety. Patients also often expect confidentiality and to be involved in choices about their own health, including where and from whom they receive care (pp: 8)

The health care provision in China, particularly the hospital industry, is dominated by state ownership and government control while the services are primarily financed by out-of-pocket spending. Quite different from many other countries, China's public health care tends to exclude the low income groups due to the relative higher direct and indirect cost while the private sector tends to serve disproportionately the low-middle income groups ${ }^{[27]}$. A survey of Chinese health patients showed widespread dissatisfaction with public providers, mainly high user fees and poor staff attitudes, is driving patients to seek cheaper but lowerquality care from poorly regulated private providers ${ }^{[26]}$.

Public complaints on China's health care system, particularly on the public hospitals, have been summarized as: "Kan Bing Gui and Kan Bing Nan", that is obtaining medical care is both expensive and difficult. The number of health care facilities and personnel in China has increased dramatically since 1980, but because of barriers to accessibility, the utilization and thus productivity of the health care sector have declined ${ }^{[28]}$. Hospital visits dropped almost $5 \%$ between 2000 and 2003, while hospital profits increased $70 \%$ over the same period ${ }^{[47]}$. A survey of 190,000 urban and rural residents conducted by China's Health Ministry in late 2003 showed that $36 \%$ of the patients in the cities and $39 \%$ in the countryside avoided seeing doctors because they could not afford medical treatment.

Consumer satisfaction with public health care delivery and its contributors has not been widely studied in China ${ }^{[36]}$. Several surveys revealed that the overall public satisfaction with public health care in China is considerably low and some possible contributing factors include high cost of health services, poor provider attitude and conflict with the health providers $^{[12,27]}$.

To improve public participation and effectiveness of the undergoing health reform initiatives in China, this research assesses consumers' satisfaction with public health care delivery in Kunming City, Yunnan Province. The study identifies the factors associated with consumers' satisfaction with the public health care delivery. 
The study is organized as follows: Introduction includes literature review on public health care, background of public health care in China and the methodology and data used. Results and discussion presents the results and the empirical findings and discussion. Lastly, Conclusion concludes the study.

Literature review: Consumer satisfaction assessment is widely used to evaluate the effectiveness of various health care services delivery, including mental health services ${ }^{[3]}$, nursing practice ${ }^{[47]}$, inpatient care $^{[18]}$ and independent consumer assistance ${ }^{[35]}$.

Different methods and instruments are used to assess consumer satisfaction ${ }^{[9,23]}$. For example, the Davis Consumer Emergency Care Satisfaction Scale (CECSS) assesses the emergency care to be reliable and valid and could be used confidently ${ }^{[19]}$. The UKUConsumer Satisfaction Rating Scale, which consists of six items related to the structure and process of treatment care and two items related to outcome and well-being, is widely used and proved to be suitable for use in ordinary clinical practice ${ }^{[1,23]}$. In other studies, consumer satisfaction assessment is conducted by asking respondents to rate their satisfaction on five key aspects of local health services (availability, geographical accessibility, choice, continuity and economic accessibility as measured by affordability) using a 5 point Likert scale ${ }^{[7,39]}$. An alternative method involves investigating consumers' experiences with actual and potential complaints in relation to health services $^{[39]}$.

However, some comparative researches conclude that differences of results are found when using different methods in analyzing consumers' satisfaction in health care services and therefore interpretation of consumers' satisfaction with their health services must take into account of the measures and research methods used and minimize possible biases in satisfaction rating scales associated with the use of particular tools ${ }^{[39]}$.

Consumer satisfaction with health care services is associated with many contributing factors, among which are related to health providers and health care delivery process. Doyle and Ware ${ }^{[11]}$ examine major dimensions of consumer perceptions on accessibility, availability of family doctors, availability of hospitals/specialists, completeness of facilities, continuity of care and physician conduct (art and technical aspects of quality) and found that physician conduct was the most important factor in general satisfaction with health care. Staff teaching efforts regarding medication or education by providers was found to be significantly associated with greater levels of satisfaction in health care in some studies ${ }^{[18,21]}$. In a study by Marriage et al. ${ }^{[31]}$ for an adolescent inpatient psychiatric unit, they identified that consumer satisfaction ratings were correlated with improvement of self-identified problems and the perceived usefulness of discharge recommendations. Gamst et al. ${ }^{[15]}$ investigate the effects of consumer-provider racial match on consumer service satisfaction of 96 outpatient consumers and conclude that client satisfaction was higher for racially matched consumers.

A study on consumer's satisfaction on Health Maintenance Organization (HMO) found that methods of practitioner compensation also have an impact on consumer satisfaction, that is, consumer satisfaction with HMOs is negatively correlated with the percentage of practitioners who are compensated on a capitationfee basis and positively correlated with the percentage of practitioners compensated with a fee-withholding incentive ${ }^{[40]}$.

Several factors related to operation and function of health facilities are found to link with consumer satisfaction in health care delivery. For example, time/availability of the services, or more flexible hours of operation, proved to be contributing factors to consumers' satisfaction ${ }^{[7,37]}$. Provision of play facilities for children was also found to be beneficial in improving consumer's satisfaction in a study on satisfaction in child health services in the nongovernment sector of Hong Kong ${ }^{[7]}$. Other studies on hospital-based social services ${ }^{[4,29]}$ reveal that consumer satisfaction with health care are positively and significantly associated with their overall rating of the social work service.

Consumer factors also have an impact on their satisfaction with the health care delivery. In a longitudinal study with 344 patients, Kumar et al. ${ }^{\text {[24] }}$ showed that consumer's experience with health care was strongly associated with satisfaction and their satisfaction was strongly associated with intent to continue using the new medication. In a study to explore the relationship between young persons' symptoms and satisfaction with child and adolescent mental health services, the researchers discovered that children and adolescents were less satisfied than their parents and those young people with self-reported conduct problems were least satisfied with the services $^{[3]}$. Another study by Rosenheck et al. ${ }^{[36]}$ revealed that consumers with better self-reported health status were more satisfied with mental health care services.

The relationship between consumers' sociodemographic characteristics and their satisfaction with medical care is widely examined, such as age, ethnicity, gender, socioeconomic status, marital status and family 
size ${ }^{[20,35]}$. For example, Rosenheck et al. ${ }^{[36]}$ identify older consumers report greater satisfaction with mental health care services. Hall and Dornan ${ }^{[20]}$ conduct a meta-analysis of 221 studies, which examines the relation of consumers' socio demographic characteristics to their satisfaction with medical care and conclude that greater satisfaction is significantly associated with greater age and less education and marginally significantly associated with being married and having higher social status. The average magnitudes of these relations are very small, with age being the strongest correlate of satisfaction. No overall relationship is found for ethnicity, gender, income, or family size.

Public health care delivery in China: After the establishment of the People's Republic of China in 1949, the Chinese government owned, funded and ran all health care facilities. Health care delivery was organized as a three-tier, bottom-up delivery system. The tiers consist of village stations, township health centers and county hospitals in the rural areas and street health stations, community health centers and district hospitals in the urban areas. At the lowest level, rural village or urban street health stations provided basic preventive and curative care and referred patients who needed additional treatment to township or community health centers. County or district hospitals provided specialized care to sick patients through an extensive network of hospitals in both urban and rural areas.

Over the past two decades China's total spending on health has grown rapidly. For example, in 1978, China's total health expenditure was RMB11 billion and increased to RMB984.3 billion (4.7\% of GDP) by 2006. Parallel to the rising expenditures on health have been major improvements in health infrastructure. Compared to 1980 , China has $67.1 \%$ more health workers and $65.3 \%$ more health institutions, including clinics in $2007^{[8]}$.

In 2007 , there were 289,538 medical service institutions, with $3,701,076$ beds; 135,105 non-profit medical institutions, constituting $46.7 \%$ of the total number of medical institutions, with $3,514,785$ beds, which accounted for $95.0 \%$ of the total number of beds. Therefore, non-profit medical institutions are still the dominant providers in China. There are a total of 4,787,610 health professionals, among them 1,644,467 are practicing doctors, 368,447 are assistant doctors and $1,543,257$ are registered nurses. The number of doctors per thousand citizens is $1.54^{[8]}$.

Given this rising level of investment, a major improvement in people's health status has taken place since 1980, but accessibility to health services has been uneven. China's life expectancy has increased from 35 years before 1949 to 71.8 years in 2001, higher than the world's average (65 years) and for middle-income countries (69 years). At the same time, the infant mortality rate has decreased from about 200 deaths per thousand live births before 1949 to 32 deaths per thousand live births in 2004, which is lower than the world's average (44 deaths per thousand live births) ${ }^{[43]}$.

Health reform in China: Since the early 1980s, China has experienced fundamental economic reform and societal transformation. In this context, the health care system has undergone incremental changes in healthcare delivery, which was characterized by fiscal decentralization and market orientation ${ }^{[6,36]}$.

First, the central government in China dramatically reduced its investment in health care services and transferred much of the responsibility to provincial and local authorities ${ }^{[6]}$. From 1978-2003, the central government's share of national health care expenditures fell from $32-15 \%{ }^{[6,32]}$.

Second, the private medical practice was legalized and encouraged since the early $1980 \mathrm{~s}^{[26]}$ and the government gradually reduced its subsidy to public hospitals, forcing them to rely more on the sale of services in the private markets to cover their expenses ${ }^{[14]}$.

Third, the Chinese government imposed strict price regulations on medicines and procedures to control health care costs for individuals and ensure accessibility to basic health care for everyone, which proved to be a failure due to overprovision of profitable high-tech services and overuse of prescriptive drugs ${ }^{[36]}$.

The coverage for medical insurance also fell sharply during the period. After the communes were abolished in 1982 in rural areas, Cooperative Medical Scheme (CMS), the only medical insurance program for farmers, collapsed rapidly. Unemployed people in the urban area also lost their employment-based medical insurance. Only $29 \%$ of Chinese people have health insurance and out-of-pocket expenses accounted for $58 \%$ of health care spending in China in $2002^{[6]}$.

The reform in health care delivery in China has failed to produce an equitable and efficient system. According to the Ministry of Health, the reform was unsuccessful $^{[16]}$. Some structural problems include reduction of accessibility to health care especially in the rural areas and reduction in insurance. This led to weaknesses in the health care delivery and health finance systems ${ }^{[2,14,22,27]}$. There is a gap in the health outcome indicators between different regions and communities including rich and poor, urban and rural and migrant and resident communities within cities. According to the evaluation of the 2000 World Health 
Report, China ranked number 144 for its health system's overall performance and 188 (the fourth from the bottom) in terms of financial contribution ${ }^{[45]}$ from a total of 191 countries. Despite the large-scale government infrastructure investment, the cost of health services remains a major barrier to accessing quality services, particularly for people in rural areas and lowincome migrants. The third Ministry of Health report ${ }^{[33]}$ reveals that in general about $48.9 \%$ of the people avoid seeing a doctor when they are ill; the most often reported reason $(38.2 \%)$ is that they could not afford the health care. In addition, $30-50 \%$ of poor people in China indicate health is the single biggest cause of their poverty due to reduced earning capacity and medical bills that can be financially ruinous ${ }^{[45]}$.

In 2007, China's health care system has 289,538 institutions including 19,852 hospitals, with 3.7 million beds. They are staffed by 4.79 million health workers, including 1.64 million doctors and 1.54 million nurses. The number of doctors per thousand citizens is 1.54 , close to the world average ${ }^{[8]}$. Similar to other urban cities in China, Kunming municipality has 2,777 health institutions, including 338 hospitals with 28,700 beds. These institutions are staffed by 33,600 health workers $^{[25]}$. Health care delivery in urban Kunming is organized as a three-tier system, which consists of street health stations, community health centers and district hospitals. In addition, there are municipal and provincial hospitals in the urban districts. In the 4 urban districts, there are approximately 200 hospitals (including provincial, municipal and district hospitals, both public and private hospitals), 41 community health centers and 83 street health stations. Most of the hospitals are public health care facilities.

However, the Chinese people see their health services far from adequate. "Expensive to receive" and "inconvenient to access" are the common complaints from the citizens. Currently, the health care delivery system in China is under enormous pressure to change in terms of demographic and epidemiological factors, rapid inflation increase in demand for services and the widening gap in health outcomes between different social groups. Recognizing these unsatisfied consequences and public discontent, China's leaders are considering another round of health care reform.

\section{MATERIALS AND METHODS}

For many commodities and services, the individual's choice is discrete and the traditional demand theory has to be modified to analyze such a choice $^{[5]}$. Let $U_{i}\left(y_{i}, w_{i}, z_{i}\right)$ be the utility function of consumer $i$, where $y_{i}$ is a dichotomous variable indicating whether the individual is satisfied with the public health care service, $w_{i}$ is the wealth of the consumer and $z_{i}$ is a vector of the consumer's characteristics. Also, let $\mathrm{c}$ be the average cost of health care, then economic theory posits that the consumer is satisfied with public health care service if:

$\mathrm{U}_{\mathrm{i}}\left(\mathrm{y}_{\mathrm{i}}=1, \mathrm{w}_{\mathrm{i}}-\mathrm{c}, \mathrm{z}_{\mathrm{i}}\right) \geq \mathrm{U}_{\mathrm{i}}\left(\mathrm{y}_{\mathrm{i}}=0, \mathrm{w}_{\mathrm{i}}, \mathrm{z}_{\mathrm{i}}\right)$

Even though the consumer's decision is straightforward, the analyst does not have sufficient information to determine whether the individual is satisfy with public health care services. Instead, the analyst is able to observe the consumer's characteristics and choice and using them to estimate the relationship between them. Let $\mathrm{x}_{\mathrm{i}}$ be a vector is of the consumer's characteristics and wealth, $\mathrm{x}_{\mathrm{i}}=\left(\mathrm{w}_{\mathrm{i}}, \mathrm{z}_{\mathrm{i}}\right)$ and then Eq. 1 can be formulated as an ex-post model given by:

$y_{i}=f\left(x_{i}\right)+\varepsilon_{i}$

where $\varepsilon_{\mathrm{I}}$ is the random term. If the random term is assumed to have a logistic distribution, then the above represents the standard binary logit model. However, if we assume that the random term is normally distributed, then the model becomes the binary probit model $^{[5,17,30]}$.

Consumers' satisfaction with public health care delivery is hypothesized to be a function of 10 variables (measured on a 5 point Likert-type scale) and demographic characteristics. The variables include interaction with providers, qualified health provider, affordable cost of public health care, comfortable public health care environment, easy physical accessibility, adequate doctors available in the public health care facilities, consumers' confidentiality respected, reasonable pricing of public health care and perception of corruption in the public health care delivery system. The demographic variables include health status, income, place of origin, age, marital status, gender, ethnic background, type of organization which the respondent works and medical insurance. The logit model will be used in this analysis because of convenience ${ }^{[30]}$. The model will be estimated using the Forced entry method in SPSS. The proposed empirical model can be written under the general form:

\footnotetext{
Consumer $=\mathrm{f}$ (Interaction, qualification, affordability,

satisfaction environment, accessibility, doctors, confidentiality, pricing, corruption, health, income, origin, age, single, male, ethnic, Org, insurance, $\varepsilon$ )
} 
Where:

Consumer satisfaction $=1$ if respondent is satisfied with public healthcare delivery, 0 otherwise

Interaction (+)

Qualification (+)

Affordability (+)

Environment (+)

Accessibility (+)

Doctor (+)

Confidentiality (+)

Pricing (+)

Corruption (-)

Health (-)

Single (+/-)

Income (+/-)

Origin (+/-)

Age (+/-)

Male (+/-)

Ethnic (+/-)

Insurance $(+/-)$

$\operatorname{Org}(+/-)$

$\varepsilon$ government or governmentowned enterprises/institutions; 0 otherwise

$=$ Error terms
The discrete dependent variable, consumer satisfaction, measures the satisfaction of the respondent with public health care delivery. This is based on the question asked in the survey, "Are you satisfied with your current public health care delivery service?"

The independent variables include interaction with providers, qualified health provider, financial affordability, public health care environment, physical accessibility, confidentiality/privacy, pricing of public health care services, adequate doctors, perceived corruption in health care system, medical insurance and socio-demographic characteristics, such as age, gender, education, income, occupation, ethnic background, place of origin and place of work.

A structured-questionnaire was used to gather the information on consumers' satisfaction on public health care delivery services in four urban districts of Kunming city (including Xishan, Wuhua, Panlong and Guandu District). For each district, three survey sites including one residence community and two public places (such as public parks, shopping malls, squares) are selected purposively for its representativeness of different social groups and considerable size of target population.

The questionnaire was translated locally in contextualized Chinese to ease understanding for the local respondents. Focus group discussion for modification of questions and pre-test were conducted before surveying the respondents to ensure appropriate questions were asked in the questionnaire. The questionnaire was designed and implemented according to the Dillman Total Design Method ${ }^{[10]}$, which has proven to result in improved response rates and data quality. The questions were phrased in the form of statements scored on a 5-point Likert-type scale, where $1=$ "strongly disagree," $3=$ "neither disagree nor agree," and 5 = "strongly agree."

Convenient sampling method is employed due to the practical difficulties in obtaining the mailing list and information of the target population including, those who have used public health care service in the last 12 months. The interview process includes: (1) The respondents must be adults of age above 18 years old and (2) The respondents must have consulted a doctor for outpatient services in the public health facilities in the past twelve months. A total of 580 Kunming local residents (both permanent resident and migrants) were interviewed generating 569 useable questionnaires $(98.1 \%)$.

\section{RESULTS AND DISCUSSION}

Descriptive statistics of respondents: The data in Table 1 presents a profile of the respondents. The composition of the respondents shows a balance in 
Table 1: Profile of respondents

\begin{tabular}{|c|c|c|}
\hline Characteristics & Frequency & Percent $(\mathrm{n}=569)$ \\
\hline \multicolumn{3}{|l|}{ Gender: } \\
\hline Male & 271 & 47.6 \\
\hline Female & 298 & 52.4 \\
\hline Total & 569 & 100.0 \\
\hline \multicolumn{3}{|l|}{ Age: } \\
\hline $18-25$ years old & 182 & 32.0 \\
\hline $26-35$ years old & 97 & 17.0 \\
\hline $36-45$ years old & 75 & 13.2 \\
\hline $46-55$ years old & 61 & 10.7 \\
\hline 56-65 years old & 73 & 12.8 \\
\hline Over 66 years old & 81 & 14.2 \\
\hline Total & 569 & 100.0 \\
\hline \multicolumn{3}{|l|}{ Ethnicity: } \\
\hline Han & 478 & 84.0 \\
\hline Non-han minority & 91 & 16.0 \\
\hline Total & 569 & 100.0 \\
\hline \multicolumn{3}{|l|}{ Origination: } \\
\hline Urban area & 452 & 79.4 \\
\hline Rural area & 117 & 20.6 \\
\hline Total & 569 & 100.0 \\
\hline \multicolumn{3}{|l|}{ Marital status: } \\
\hline Single/never married & 213 & 37.4 \\
\hline Married & 316 & 55.5 \\
\hline Divorced/separated & 17 & 3.0 \\
\hline Widowed & 23 & 4.0 \\
\hline Total & 569 & 100.0 \\
\hline \multicolumn{3}{|l|}{ Education: } \\
\hline Illiterate & 26 & 4.6 \\
\hline Primary School & 59 & 10.4 \\
\hline Secondary School & 90 & 15.8 \\
\hline High school/Vocational & 142 & 25.0 \\
\hline Bachelor degree & 215 & 37.8 \\
\hline Postgraduate degree & 37 & 6.5 \\
\hline Total & 569 & 100.0 \\
\hline \multicolumn{3}{|l|}{ Occupation: } \\
\hline Managers/owner & 57 & 10.0 \\
\hline Office staff & 68 & 12.0 \\
\hline Professional & 49 & 8.6 \\
\hline Businessman & 18 & 3.2 \\
\hline Service staff & 57 & 10.0 \\
\hline Laborer & 18 & 3.2 \\
\hline Policeman/soldier & 6 & 1.1 \\
\hline Unemployed & 44 & 7.7 \\
\hline Retired & 79 & 13.9 \\
\hline Student & 112 & 19.7 \\
\hline House person & 15 & 2.6 \\
\hline Others & 46 & 8.1 \\
\hline Total & 569 & 100.0 \\
\hline \multicolumn{3}{|l|}{ Income } \\
\hline US\$ 350 or less & 43 & 7.6 \\
\hline US\$ 350-US\$1,400 & 109 & 19.2 \\
\hline US\$ 1,401 -US\$ 2,800 & 135 & 23.7 \\
\hline US $\$ 2,801$-US $\$ 4,200$ & 87 & 15.3 \\
\hline US\$ 4,201-US\$ 7,000 & 29 & 5.1 \\
\hline US\$ $7,001-U S \$ 14,000$ & 19 & 3.3 \\
\hline More than US\$ 14,000 & 5 & 0.9 \\
\hline No income & 142 & 25.0 \\
\hline Total & 569 & 100.0 \\
\hline \multicolumn{3}{|c|}{ Family members living in Kunming: } \\
\hline 1 person & $133^{\circ}$ & 0.9 \\
\hline $2-3$ persons & 242 & 23.4 \\
\hline $4-5$ persons & 149 & 42.5 \\
\hline More than 5 persons & 40 & 26.2 \\
\hline (Missing variables) & 5 & 7.0 \\
\hline Total & 569 & 100.0 \\
\hline \multicolumn{3}{|c|}{ Duration living in Kunming: } \\
\hline Less than 1 year & 16 & 2.8 \\
\hline $1-5$ years & 203 & 35.7 \\
\hline More than 5 years & 350 & 61.5 \\
\hline Total & 569 & 100.0 \\
\hline
\end{tabular}

gender with $47.6 \%$ male and $52.4 \%$ female and covers various types of occupations including $19.7 \%$ students, $13.9 \%$ retired people, $12.0 \%$ office staff, $10.0 \%$ managers/owners, $10.0 \%$ service staff and others (professionals, businessman, labor, unemployed). Approximately $55.5 \%$ of the respondents are married and $37.4 \%$ never married. Majority of the respondents are of Han nationality $(84.0 \%)$, living in Kunming over 5 years $(61.5 \%)$, in a family with $2-5$ people $(65.9 \%)$, with origin of urban area $(79.4 \%)$ and received secondary school or higher education $(85.1 \%)$. One-fourth of the respondents, who are mainly students, have no income, but most of the respondents $(58.2 \%)$ have an annual income of US\$350-4,200, 23.7\% with an income of US\$1,401$2,800,19.2 \%$ with an income of US\$350-1,400 and $15.3 \%$ with an income of US\$2,801-4,200 (Table 1).

From the 569 respondents, $82.5 \%$ of the respondents reported their health status as good or fair and $85.6 \%$ of them have been involved in one health care insurance or medical aid scheme. In addition, $61.5 \%$ of the respondents were satisfied with the public health care services in Kunming, while $38.5 \%$ were dissatisfied.

Our results reveal that $56.2 \%$ of the respondents have visited the public health care facilities at least twice in the past 12 months. Over half of the respondents $(52.4 \%)$ reported that provincial and municipal hospitals were the most often used public health care facility for common diseases, while less than one-fourth $(24.9 \%)$ reported community health centers and stations as most often used public health care facilities (Table 2).

The availability of specific health care $(22.5 \%)$, the convenience of accessibility $(22.1 \%)$ and good quality care $(20.2 \%)$ were the most often mentioned reasons for using public health care (Table 2). Quality of care and affordability were ranked by the respondents as the most important factors influencing their satisfaction with health care (Table 3), while over half of the respondents $(58.0 \%)$ reported they were dissatisfied or very dissatisfied with the affordability of current public health care delivery and only $12.6 \%$ respondents were satisfied (Table 4).

Empirical analysis: The items used to measure each construct were tested for reliability by using a Cronbach's Alpha value of 0.60 as the cut-off point (Table 5). A value of 0.60 or more indicates satisfactory internal consistency reliability in exploratory studies. The scores of the items (questions) representing each construct are totaled and a mean score was calculated for each construct. Using these means, together with the demographic characteristics the logit equation was estimated. 
J. Social Sci., 5(3): 223-235, 2009

Table 2: General health information of the respondents

\begin{tabular}{|c|c|c|}
\hline Health information & Frequency & $\begin{array}{l}\text { Percent } \\
(\mathrm{n}=569)\end{array}$ \\
\hline \multicolumn{3}{|l|}{ Satisfaction with PHC: } \\
\hline Satisfied & 350 & 61.5 \\
\hline Not satisfied & 219 & 38.5 \\
\hline Total & 569 & 100.0 \\
\hline \multicolumn{3}{|l|}{ Health status: } \\
\hline Excellent & 68 & 12.0 \\
\hline Good & 195 & 34.3 \\
\hline Fair & 206 & 36.2 \\
\hline Poor & 93 & 16.3 \\
\hline Very poor & 7 & 1.2 \\
\hline Total & 569 & 100.0 \\
\hline \multicolumn{3}{|l|}{ Deal with sickness: } \\
\hline Do nothing & 28 & 4.9 \\
\hline Self-care/family-care & 201 & 35.3 \\
\hline Seek help in a drug store & 234 & 41.1 \\
\hline See a doctor at a public health & 77 & 13.5 \\
\hline See a doctor at a private health & 26 & 4.6 \\
\hline Other & 3 & 0.5 \\
\hline Total & 569 & 100.0 \\
\hline \multicolumn{3}{|l|}{ Visits to PHC: } \\
\hline 1 time & 249 & 43.8 \\
\hline 2 times & 139 & 24.4 \\
\hline 3 times & 70 & 12.3 \\
\hline 4 times & 39 & 6.9 \\
\hline 5 times & 25 & 4.4 \\
\hline 6 times or more & 47 & 8.3 \\
\hline Total & 569 & 100.0 \\
\hline \multicolumn{3}{|l|}{ Most often used PHC: } \\
\hline Provincial hospitals & 150 & 26.4 \\
\hline Municipal hospitals & 148 & 26.0 \\
\hline District hospitals & 127 & 22.3 \\
\hline Community health centers & 78 & 13.7 \\
\hline Community health stations & 64 & 11.2 \\
\hline Missing & 2 & 0.4 \\
\hline Total & 569 & 100.0 \\
\hline \multicolumn{3}{|l|}{ Reasons for using PHC: } \\
\hline The health care I want available & 126 & 22.1 \\
\hline It is convenient to visit the $\mathrm{PHC}$ & 128 & 22.5 \\
\hline The cost is affordable & 27 & 4.7 \\
\hline I have insurance to pay for services & 73 & 12.8 \\
\hline My health insurance contract with PHC & 54 & 9.5 \\
\hline Good quality of care & 115 & 20.2 \\
\hline Other & 45 & 7.9 \\
\hline Missing & 1 & 0.2 \\
\hline Total & 569 & 100.0 \\
\hline \multicolumn{3}{|c|}{ Percentage of cost covered by insurance: } \\
\hline All the cost & 18 & 3.2 \\
\hline $75-100 \%$ & 68 & 12.0 \\
\hline $50-75 \%$ & 66 & 11.6 \\
\hline $25-50 \%$ & 56 & 9.8 \\
\hline$<25 \%$ & 50 & 8.8 \\
\hline Not at all & 213 & 37.4 \\
\hline Can not remember & 97 & 17.0 \\
\hline Missing & 1 & 0.2 \\
\hline Total & 569 & 100.0 \\
\hline \multicolumn{3}{|l|}{ Medical insurance: } \\
\hline Government medical insurance & 63 & 11.5 \\
\hline Labor medical insurance & 54 & 9.8 \\
\hline Urban employee basic medical insurance & 110 & 20.0 \\
\hline Urban resident basic medical insurance & 69 & 12.6 \\
\hline Rural cooperative medical scheme & 81 & 14.8 \\
\hline Business medical insurance & 83 & 15.1 \\
\hline Urban or rural medical aid & 22 & 4.0 \\
\hline
\end{tabular}

Table 2: Continued

\begin{tabular}{lrr}
\hline Other medical insurance & 20 & 3.6 \\
No medical insurance & 82 & 14.9 \\
Total & 584 & $106.4^{*}$ \\
Non-public alternatives: & & \\
Private hospital & 28 & 4.9 \\
Private clinic & 61 & 10.7 \\
Drugstore & 268 & 47.1 \\
Self-care/family-care & 147 & 25.8 \\
Do nothing' & 16 & 2.8 \\
Not applicable & 42 & 7.4 \\
Other & 7 & 1.2 \\
Total & 569 & 100.0 \\
Reasons for using non-public alternatives: & & \\
The health care I want not available & 14 & 2.5 \\
It is not convenient to visit PHC & 75 & 13.2 \\
It was too expensive to visit PHC & 249 & 43.8 \\
Poor quality of care & 37 & 6.5 \\
Poor doctor attitude & 47 & 8.3 \\
Others & 42 & 7.4 \\
Not applicable & 104 & 18.3 \\
Missing & 1 & 0.2 \\
Total & 569 & 100.0 \\
Likelihood of using PHC in the future: & & \\
Very likely & 146 & 25.7 \\
Somewhat likely & 214 & 37.6 \\
Neither & 162 & 28.5 \\
Somewhat unlikely & 34 & 6.0 \\
Very unlikely & 13 & 2.3 \\
Total & 569 & 100.0 \\
\hline * This is a multipe-choice question & & \\
\hline
\end{tabular}

*: This is a multiple-choice question

Table 3: Public perception on importance of five aspects of public health care

\begin{tabular}{lllllll}
\hline Five aspects & $\mathrm{N}$ & Min & Max & Mean & Std. deviation & Rank \\
\hline Availability & 566 & 1 & 5 & 3.43 & 1.271 & 3 \\
Convenience & 565 & 1 & 5 & 3.66 & 1.256 & 5 \\
Affordability & 566 & 1 & 5 & 2.39 & 1.344 & 2 \\
Environment & 567 & 1 & 5 & 3.63 & 1.067 & 4 \\
Quality of care & 567 & 1 & 5 & 1.90 & 1.135 & 1
\end{tabular}

The estimated logit results are presented in Table 6. In general, the model fitted the data quite well. The likelihood ratio chi-square of 120.862 with a p-value of 0.0001 shows the model fitted the data quite well. The chi-square test strongly rejected the hypothesis of no explanatory power. The Force Entry Method shows the estimated logit model can correctly predict $64.4 \%$ of dissatisfied customers and $85.1 \%$ of satisfied customers. The overall proportion of correct classification is $77.1 \%$.

The estimated coefficients indicate that five out of the nine factors are statistically significant at the 5\% level of significance in influencing consumer satisfaction with public health care delivery, that is, qualified doctors, financial affordability, adequate doctor, pricing and corruption while the other four factors, interaction with providers, environment, physical accessibility and confidentiality did not show statistically significant relationship with consumer satisfaction. 
J. Social Sci., 5(3): 223-235, 2009

Table 4: Consumer satisfaction with five aspects of public health care

\begin{tabular}{lcccccccc}
\hline \multicolumn{2}{l}{ Five aspects $(\mathrm{n}=569)$} & Very unsatisfied & Unsatisfied & Neither & Satisfied & Very satisfied & Missing & Total \\
\hline Availability & $\mathrm{N}$ & 23.0 & 79.0 & 228.0 & 234.0 & 5.0 & 0.0 & 569.0 \\
& $\%$ & 4.0 & 13.9 & 40.1 & 41.1 & 0.9 & 0.0 & 100.0 \\
Convenience & $\mathrm{N}$ & 13.0 & 81.0 & 192.0 & 259.0 & 21.0 & 3.0 & 569.0 \\
& $\%$ & 2.3 & 14.2 & 33.7 & 45.5 & 3.7 & 0.5 & 100.0 \\
Affordability & $\mathrm{N}$ & 89.0 & 241.0 & 168.0 & 68.0 & 2.0 & 1.0 & 569.0 \\
& $\%$ & 15.6 & 42.4 & 29.5 & 12.0 & 0.4 & 0.2 & 100.0 \\
Environment & $\mathrm{N}$ & 21.0 & 118.0 & 230.0 & 194.0 & 5.0 & 1.0 & 569.0 \\
& $\%$ & 3.7 & 20.7 & 40.4 & 34.1 & 0.9 & 0.2 & 100.0 \\
Quality & $\mathrm{N}$ & 24.0 & 80.0 & 228.0 & 227.0 & 10.0 & 0.0 & 569.0 \\
& $\%$ & 4.2 & 14.1 & 40.1 & 39.9 & 1.8 & 0.0 & 100.0 \\
\hline
\end{tabular}

Table 5: Cronbach's alpha and reliability test

\begin{tabular}{|c|c|c|c|}
\hline Constructs & Items & Rotated loading & Alpha \\
\hline \multirow[t]{7}{*}{ Interaction } & e02-The health care providers spend enough time with me in the examination room & 0.745 & 0.833 \\
\hline & d03-I have enough time to interact with my doctor in the examination room & 0.723 & \\
\hline & e08-I am well involved in the decisions made about my care & 0.649 & \\
\hline & e01-The health care providers listen carefully to my problems & 0.604 & \\
\hline & e06-The health care providers are friendly to me & 0.454 & \\
\hline & e12-In general, I feel comfortable with my health provider & 0.427 & \\
\hline & e03-The health care providers clearly speak to me in a way that I can understand & 0.364 & \\
\hline \multirow[t]{5}{*}{ Qualification } & d04-The treatment provided by my doctor adequately addressed my health concerns & 0.722 & 0.817 \\
\hline & e04-The health care providers address my health concerns & 0.694 & \\
\hline & e05-I trust the advice my doctor gives me & 0.629 & \\
\hline & d10-In general, the public health care facilities in my city meet my expectations & 0.514 & \\
\hline & d09-The service providers are well qualified & 0.498 & \\
\hline \multirow[t]{6}{*}{ Affordability } & c09-I have had to give up my treatment plan because I could not afford it & 0.752 & 0.743 \\
\hline & c08-I need to borrow money to pay for health care & 0.735 & \\
\hline & c07-I have to use my family savings to pay for health care & 0.680 & \\
\hline & c10-In general, the public health care facilities in my city are affordable & 0.653 & \\
\hline & c05-Indirect costs prevent me from visiting the health facility & 0.507 & \\
\hline & e09-I am likely to receive a miss-diagnosis or wrong treatment during my visit to PHC & 0.377 & \\
\hline \multirow[t]{4}{*}{ Environment } & d06-The facilities in the center are well equipped & 0.732 & 0.706 \\
\hline & d07-The overall environment in the center is comfortable & 0.694 & \\
\hline & d08-The health center is safe and clean & 0.656 & \\
\hline & d05-The process involved in receiving medical treatment is easy for me to follow & 0.352 & \\
\hline \multirow[t]{4}{*}{ Accessibility } & b01-The health care centre is located close to my home & 0.795 & 0.711 \\
\hline & b02-Transportation is easily accessible to take me to and from the health care centre & 0.738 & \\
\hline & b03-It takes me a long time to get to the health care center & 0.691 & \\
\hline & b08-The location of the public health care facilities in my city are accessible to me & 0.517 & \\
\hline \multirow{4}{*}{ Doctors } & a04-There are sufficient doctors in the public health facilities & 0.738 & 0.715 \\
\hline & e11-The number of health care workers is sufficient to meet the demands & 0.631 & \\
\hline & a05-In general, the existing public health services meet my needs & 0.547 & \\
\hline & a03-All of my health care needs can be met by the public health facilities and services & 0.505 & \\
\hline \multirow[t]{2}{*}{ Confidentiality } & $\mathrm{e} 07-$ The health care providers keep my personal information private & 0.768 & 0.724 \\
\hline & e10-The doctor respects my privacy & 0.718 & \\
\hline \multirow[t]{2}{*}{ Pricing } & c02-The price of examination in public health facilities is reasonable & 0.812 & 0.816 \\
\hline & c01-The drug cost charged by the health facilities is reasonable & 0.801 & \\
\hline \multirow[t]{2}{*}{ Corruption } & b04-Having an acquaintance will better facilitate my visit to PHC & 0.798 & 0.640 \\
\hline & c04-Offering bribes to health care providers will better facilitate my visit to PHC & 0.733 & \\
\hline
\end{tabular}

Among the nine demographic variables examined in this study, age (36-55 years), marital status (single), nationality (Han), insurance and organization were found to be statistically significant in influencing consumer satisfaction with public health care delivery at the $5 \%$ level of significance (Table 6).

Our result shows corruption, as hypothesized, has a negative impact on the likelihood that the consumer is satisfied with public health care delivery. The exponentiated coefficient equals 0.676 , indicating if consumers' perceived corruption level increases by 1 unit, the odds value decreases from 1 to 0.676 , hence decreases the probability of being satisfied with the public health care delivery. In other words, if the consumer perceived corruption exists in public health care delivery, for example, offering bribes to health care providers will better facilitate health care seeking process in public health care facilities, he/she is less likely to be satisfied with the public health care delivery. 
Table 6: Logistic regression results

\begin{tabular}{lrlrlll}
\hline \multicolumn{1}{c}{$\mathrm{B}$} & $\mathrm{SE}$ & Wald & df & Sig. & Exp (B) \\
\hline Interaction & 0.550 & 0.371 & 2.194 & 1 & 0.139 & 1.733 \\
Qualification & 0.987 & 0.361 & 7.470 & 1 & $0.006^{*}$ & 2.684 \\
Affordability & 0.978 & 0.245 & 15.884 & 1 & $0.000^{*}$ & 2.658 \\
Environment & -0.308 & 0.291 & 1.120 & 1 & 0.290 & 0.735 \\
Accessibility & -0.375 & 0.241 & 2.431 & 1 & 0.119 & 0.687 \\
Doctors & 0.541 & 0.272 & 3.954 & 1 & $0.047 *$ & 1.717 \\
Confidentiality & -0.225 & 0.268 & 0.706 & 1 & 0.401 & 0.799 \\
Pricing & 0.426 & 0.191 & 4.989 & 1 & $0.026^{*}$ & 1.532 \\
Corruption & -0.392 & 0.170 & 5.297 & 1 & $0.021 *$ & 0.676 \\
Health & 0.198 & 0.409 & 0.235 & 1 & 0.628 & 1.219 \\
Income & 0.060 & 0.353 & 0.029 & 1 & 0.865 & 1.062 \\
Origin & -0.176 & 0.382 & 0.214 & 1 & 0.644 & 0.838 \\
Age & 0.883 & 0.385 & 5.247 & 1 & $0.022^{*}$ & 2.417 \\
Single & 0.948 & 0.378 & 6.291 & 1 & $0.012 *$ & 2.579 \\
Male & -0.014 & 0.314 & 0.002 & 1 & 0.963 & 0.986 \\
Ethnic group (Han) & 0.920 & 0.426 & 4.663 & 1 & $0.031 *$ & 2.510 \\
Medical insurance & 0.853 & 0.416 & 4.205 & 1 & $0.040 *$ & 2.346 \\
Organization & 0.770 & 0.356 & 4.685 & 1 & $0.030^{*}$ & 2.161 \\
Constant & -8.078 & 1.643 & 24.163 & 1 & 0.000 & 0.000 \\
\hline
\end{tabular}

*: Significant at 5\% level. Number of Observations: 569; -2 LogLikelihood: 287.188; Chi-squared Statistics: 120.862; Degrees of Freedom: 18; Significance Level: 0.000 ; \% Predicted Right: $77.1 \%$

Consistent with the prior hypotheses ${ }^{[7,11]}$, qualified doctors, financial affordability, adequate doctor and reasonable pricing positively affect the probability of the consumers' satisfaction with the public health care delivery. Qualification has the largest exponentiated coefficient, 2.684, implying doctor's qualification is the most indicative predictor of increasing consumers' level of satisfaction toward healthy care delivery. When consumer's perceived doctor qualification increase by one unit, its odds values increases by $168.4 \%$. The second most indicative predictor is financial affordability, with the exponentiated coefficient equals 2.658 (or odds value increase by $165.8 \%$ ), followed by adequate doctors, exponentiated coefficient equals 1.717 (or odds value increase by $71.7 \%$ ) and pricing, exponentiated coefficient equals 1.532 (or odds value increase by $53.2 \%$ ).

If a consumer considers his/her health care providers as qualified or his/her health concern/problems are well addressed by public health care providers, he/she is more likely to be satisfied with the public health care delivery. Similarly, if there are sufficient doctors in the public health care facilities and they do not need to wait for a long time before seeing a doctor, their possibility of being satisfied increases. Our result is consistent with findings in previous studies $^{[11,18,21]}$.

Financial affordability and reasonable pricing of public health care services were found to have strong positive correlations with consumers' satisfaction with public health care delivery. If the public health services are affordable to the consumer or he/she perceived the pricing of public health care services as reasonable, he/she is more likely to feel satisfied. In other words, if people consider public health care services as too expensive, they are less likely to be satisfied. This result confirms our findings from the survey that Chinese people complain most about the expensive public health care services. The financial burden caused by the health care and discontentment of corruption in the public health care delivery lessen the consumers' likelihood to be satisfied.

The socio-demographic variables, including gender, income, education, occupation, origin and health status, are insignificant in explaining the respondents' probability in being satisfied with public health care delivery except for: Maritall (single), Age2 (age 36-55), Ethnicity (Han), Insurance and Organization (public).

Age2 (age 36-55) positively affects the probability of the consumer being satisfied with public health care delivery, which means if the consumer is in the age group of $36-55$ years, he/she is more likely to be satisfied with the public health care delivery (Table 6). This is consistent with ${ }^{[35]}$ findings, where older consumers report greater satisfaction with mental health care services.

Our result also reveals that if the consumer is single, the likelihood of he/she being satisfied with the public health care delivery increases (exponential coefficient $=2.417$ ). This is probably because majority of unmarried people interviewed in the survey are students and office clerk, who have high coverage of medical insurance with good reimbursement scheme. Furthermore, students have access to public health centers on university campuses.

Our result also show consumers who belong to the Han group (majority ethnic group in China), have medical insurance, or work for the government or government-owned enterprises/institutions are more likely to be satisfied with the public health care delivery. Government or government-owned enterprises/institutions in China provide a better benefit package, including higher percentage of cost covered by public funding for public health care services, which may explain why people working in these sectors are more likely to be satisfied with public health care delivery.

In contrast with the literatures, four variables are found to be insignificant to explain consumers' satisfaction toward public health care delivery, interaction (with health care providers), environment ${ }^{[11]}$, confidentiality and accessibility ${ }^{[11]}$. The possible explanation for interaction, environment and confidentiality is that these variables are perceived more as extended service level rather than minimum service level. 
Health care system in Kunming is still in the developing stage and hence consumers would be more sensitive to the minimum service level factors (qualification, adequate doctors, affordability and pricing). Therefore, when 9 variables are considered, only the minimum service level factors reflect to be significant in explaining consumers' satisfaction. In terms of accessibility, it is probably attributed that health care facilities are generally conveniently located in the urban area of Kunming. Moreover, because this study focused on consumers who have been to public health care services and they have given relatively high ratings (convenience have highest mean of 3.66 among 5 variables asked). The access level of public health care services are generally well accepted, therefore, it may not be an important factor to determine the probability of being satisfied.

\section{CONCLUSION}

Previous researchers have examined the relationship between peoples' satisfaction with health care and effectiveness of the health care delivery. Many factors have been identified as having influences on consumer satisfaction with health care, including provider conduct, health education by providers, availability of the services, consumers' perceived improvement of self-reported problems and sociodemographic factors, such as age and marital status. However, the findings in most studies have been ambiguous in linking affordability and accessibility of health care delivery with consumer satisfaction, which is a concern for most people in urban China.

Our finding shows $61.5 \%$ of the respondents were satisfied with the health care delivery. Quality of care and affordability are ranked by the respondents as the most important factors influencing their satisfaction with the health care. The logit regression also have similar findings, qualified doctors and adequate doctors and affordable costs and reasonable pricing of public health services significantly increase the likelihood of the consumer's satisfaction with the public health care delivery. Qualification has the most chance to increase the probability of having satisfied consumers on public health care delivery and followed by affordability, doctors and pricing. In addition, our logistic regression results also reveal that corruption has a negative impact on consumer satisfaction of public health care delivery.

Most socio-demographic variables, including gender, income, education, occupation, residency and health status are insignificant in explaining the respondents' probability of being satisfied with public health care delivery. However, specific groups of marital status, age, ethnicity, medical insurance and working organizations have significant relationships with satisfaction with public health care delivery. Consumers who are single/never married, in the middle age group (36-55 years old), belong to Han ethnicity group, have medical insurance, or works for government/government-funded institutions are more likely to be satisfied with the public health care delivery.

Our finding reveals that satisfaction level with public health care delivery in China is relatively low, particularly in terms of affordability of public health care $($ mean $=2.39)$. The result clearly shows that the current public health care delivery system fails to achieve one of the three fundamental goals of health systems, responsiveness to consumers. For the undergoing health reform in China, it is suggested that consumer perspectives on health care delivery system should be further studied and public involvement in decision-making process should be strengthened, so as to ensure the system would better respond to public expectations. Furthermore, health managers or policy makers should make efforts to improve the current health care delivery system by promoting a clientoriented health care system. This study shows that consumers' satisfaction level in Kunming city is still based on the minimum service level factors, strengthening the qualification of providers and adequate doctors, as well as developing more affordable health care services are the first priorities for enhancing consumers' satisfaction. Moreover, corruption should be avoided in the delivery of health care, as consumers perceived it as a threat to increase their likelihood of being satisfied.

\section{ACKNOWLEDGEMENT}

We would like to thank the Mekong Institute and New Zealand's International Aid and Development Agency (NZAID) for funding this study.

\section{REFERENCES}

1. Ahlfors, U.G., T. Lewander, E. Lindstrom, U.F. Malt, H. Lublin and U. Malm, 2001. Assessment of Patient satisfaction with psychiatric care development and clinical evaluation of a brief consumer satisfaction rating scale (UKU-ConSat). Nord. J. Psychiatry, 55: 71-90. http://www.ncbi.nlm.nih.gov/pubmed/11860667

2. Asian Development Bank, 1999. Country presentations-China. Second Meeting of the Working Group on Human Resource Development. 
3. Barber, A.J., V.A. Tischler and E. Healy, 2006. Consumer satisfaction and child behavior problems in child and adolescent mental health services. J. Child Health Care, 10: 9-21.

4. Beatty, P.W., G.W. Richmond and S. Tepper, 1998. Personal assistance for people with physical disabilities: Consumer-direction and satisfaction with services. Arch. Phys. Med. Rehabilitat., 79: 674-677. http://www.ncbi.nlm.nih.gov/pubmed/9630148

5. Ben-Akiva, M. and S. Lerman, 1985. Discrete Choice Analysis. MIT Press, Cambridge, ISBN: 0262022176, pp: 390.

6. Blumenthal, D. and W. Hsiao, 2005. Privatization and its discontents: The evolving Chinese health care system. N. Engl. J. Med., 353: 1165-1170. http://www.ncbi.nlm.nih.gov/pubmed/16162889

7. Chan, S.S. and S. Twinn, 2003. Satisfaction with child health services in the non-government sector of Hong Kong: Consumer evaluation. Nurs. Health Sci., 5: 165-173.

8. China Health Statistical Yearbook, 2008.

9. Davis, B.A., C.K. Kiesel, J. McFarland, A. Collard, K. Coston and A. Keeton, 2005. Evaluating instruments for quality: Testing convergent validity of the consumer emergency care satisfaction scale. J. Nurs. Care Qual., 20: 364-368. http://www.ncbi.nlm.nih.gov/pubmed/16177589

10. Dilliman, D.A., 1978. Mail and Telephone Surveys: The Total Design Method. John Wiley and Sons, ISBN:13: 978-0471215554, pp: 344.

11. Doyle, B.J. and J.E. Ware, 1977. Physician conduct and other factors that affect consumer satisfaction with medical care. J. Med. Educ., 52: 793-801. http://www.ncbi.nlm.nih.gov/pubmed/903944

12. Eggleston, K., L. Ling, M. Qingyue, M. Lindelow and A. Wagstaff, 2008. Health service delivery in China: A literature review. Health Econ., 17: $149-165$.

http://ideas.repec.org/a/wly/hlthec/v17y2008i2p14 9-165.html

13. European Observatory on Health Care Systems, 2002. Health care systems in eight countries: Trends and Challenges. London School of Economics and Political Science Hub, London, UK. http://eprints.lse.ac.uk/19949/

14. Fan, W., Y. Liu, O. Bhattacharyya, L. Hu and A. Chu, 2007. Equity and efficiency of china's healthcare delivery system. Proceeding of the 135th APHA Annual Meeting and Exposition of APHA, Nov. 37, Washington, American Public Health Association. http://apha.confex.com/apha/135am/techprogram/p aper_157937.htm
15. Gamst, G., A. Aguilar-Kitibutr, A. Herdina, S. Hibbs, E. Krishtal and R. Lee et al., 2003. Effects of racial match on asian american mental health consumer satisfaction. Mental Health Servic. Res., 5: 197-208. http://www.ncbi.nlm.nih.gov/pubmed/14672499

16. Gao, Q., 2005. Ministry of Health Report on China's Healthcare System and Reform, Ministry of Health of China.

17. Goto, H., Y. Hasegawa and M. Tanaka, 2007. Efficient scheduling focusing on the duality of MPL representatives. Proceedings of the IEEE Symposium on Computational Intelligence in Scheduling, Dec. 2007, IEEE Xplore Press, USA., pp. 57-64. DOI: 10.1109/SCIS.2007.357670

18. Greene, W., 1990. Econometric Analysis. Palgrave MacMillan, New York, ISBN: 10: 0333495519.

19. Hackman, A., C. Brown, Y. Yang, R. Goldberg and J. Kreyenbuhl et al., 2007. Consumer satisfaction with inpatient psychiatric treatment among persons with severe mental illness. Communit. Mental Health J., 43: 551-564. DOI: 10.1007/s10597-007-9098-3

20. Hall, J.A. and M.C. Dornan, 1990. Patient socio demographic characteristics as predictors of satisfaction with medical care: A meta-analysis. Soc. Sci. Med., 30: 811-818. http://www.ncbi.nlm.nih.gov/pubmed/2138357

21. Howard, P.B., J.J. Clark, M.K. Rayens and V. Hines-Martin, 2001. Consumer satisfaction with services in a regional psychiatric hospital: A collaborative research project in Kentucky. Arch. Psychiatry Nurs., 15: 10-23.

22. International Monetary Fund, 2006. Healthcare in China: Toward greater access, efficiency and quality. IBM Business Consulting Services: Healthcare, IBM Institute for Business Value. http://jobfunctions.bnet.com/abstract.aspx ?docid=9 00465

23. Ivarsson, B. and U. Malm, 2007. Self-reported consumer satisfaction in mental health services: Validation of a self-rating version of the UKUconsumer satisfaction rating scale. Nord. J. Psychiatry, 61: 194-200.

http://www.informaworld.com/smpp/ftinterface?content $=\mathrm{a} 779024127 \& \mathrm{rt}=0 \&$ format $=\mathrm{pdf}$

24. Kumar, R.N., D.M. Kirking, S.L. Hass, A.D. Vinokur and S.D. Taylor, 2007. The association of consumer expectations, experiences and satisfaction with newly prescribed medications. Qual. Life Res., 16: 1127-1136. http://www.ncbi.nlm.nih.gov/pubmed/17530445

25. Kunming Statistical Yearbook, China, 2007. 
26. Lim, M.K., H. Yang, T. Zhang, W. Feng and Z. Zhou, 2004. Public perceptions of private health care in socialist China. Health Affairs, 23: 222-234. http://www.ncbi.nlm.nih.gov/pubmed/15537602

27. Liu, Y., P. Bermana, W. Yip, H. Liang, Q. Mengc, J. Quc and Z. Li, 2006. Health care in China: The role of non-government providers. Health Policy, 77: 212-220. http://www.ncbi.nlm.nih.gov/pubmed/16112771

28. Liu, Y., K. Rao and S. Hu, 2002. People's republic of China: Toward establishing a rural health protection system. Asian Development Bank. http://www.adb.org/Documents/Reports/PRC_Rural_He alth_Protection_System/default.asp

29. McNeill, T., D. Nicholas and K. Szechy, 1998. Perceived outcome of social work intervention: Beyond consumer satisfaction. Social Work Health Care, 26: 1-18. http://www.ncbi.nlm.nih.gov/pubmed/9456471

30. Maddala, G.S., 1993. Limited Dependent and Qualitative Variables in Econometrics. Cambridge University Press, Cambridge, ISBN: 9780521338257.

31. Marriage, K., J. Petrie and D. Worling, 2001. Consumer satisfaction with an adolescent inpatient psychiatric unit. Can. J. Psychiatry, 46: 969-795. http://www.ncbi.nlm.nih.gov/pubmed/11816320

32. Mei, H. and X. Wang, 2006. China's budget system and the financing of education and health services for children. Beijing, China, UNICEF, NWCCW. http://www.unicef.org/china/Budget_study_Englis h.pdf

33. Ministry of Health, China, 2004. An analysis report of national health services survey in 2003. Beijing, China Union Medical University Publish House.

34. Ministry of Health, 2008. China Health Statistical Yearbook.http://www.moh.gov.cn/publicfiles/busin ess/htmlfiles/zwgkzt/ptjnj/year2008/1.htm

35. Nascimento, L.M. and M.R. Cousineau, 2005. An evaluation of independent consumer assistance centers on problem resolution and user satisfaction: the consumer perspective. J. Communit. Health, 30: 89-106.

http://www.ncbi.nlm.nih.gov/pubmed/15810563

36. Rosenheck, R.A., N.J. Wilson and M. Meterko, 1997. Influence of patient and hospital factors on consumer satisfaction with inpatient mental health treatment. Psychiatry Service, 48: 1553-1561. http://psychservices.psychiatryonline.org/cgi/conte nt/abstract/48/12/1553
37. Sai, M. and S. Neeraj, 2008. A comparison of the health systems in China and India. The RAND Corporation Occasional Paper, Center for Asia Pacific Policy. http://www.rand.org/pubs/occasional_papers/2008/ RAND_OP212.pdf

38. Samuelsson, G. and A. Wister, 2000. Client expectations and satisfaction of quality in home care services: A consumer perspective. Home Care Provid., 5: 223-30. http://www.ncbi.nlm.nih.gov/pubmed/11113785

39. Samson, M.R., 2001. Healing cambodia's health system NGOs are being tapped as new partners to deliver services for better health care. Asian Develop. Bank Rev., 33:

40. Smith, K.B., J.S. Humphreys and J.A. Jones, 2006. Essential tips for measuring levels of consumer satisfaction with rural health service quality. Rural Remote Health, 6: 594-594. http://www.ncbi.nlm.nih.gov/pubmed/17115877

41. Scoggins, J.F., 2002. The effect of practitioner compensation on HMO consumer satisfaction. Manage. Care, 11: 49-52. http://www.ncbi.nlm.nih.gov/pubmed/11980228?d opt $=$ Abstract

42. Tang, Y., 2005. Ninety Percent Public Expressed Dissatisfaction with Health Care Reform. China Youth Newspaper, Beijing.

43. Wang, S., 2004. China's Health System: From Crisis to Opportunity. Yale-China Health Journal 3: 5-49.

44. WHO, 2000. The World Health Report 2000Health System: Improving Performance. http://www.who.int/whr/2000/en/whr00_en.pdf

45. World Health Organization, 2008. Health Care Delivery. http://www.euro.who.int/healthcaredelivery

46. Wortans, J., B. Happell and H. Johnstone, 2006. The role of the nurse practitioner in psychiatric/mental health nursing: Exploring consumer satisfaction. J. Psychiatr. Mental Health Nurs., 13: 78-84. http://dialnet.unirioja.es/servlet/articulo? codigo $=13$ 84799

47. Yu, Y., 2006. Market economy and social justice: The predicament of the underprivileged. J. Comparat. Asian Develop., 5: 199-215. https://louisville.edu/asiandemocracy/conferences/1 inks-and-images/06-yu.pdf 